\title{
Study of Rheological Property and Flow Behavior for Nanoparticles Enhanced VES System in Porous Media
}

\author{
Zhaoxia Liu *, Qiang Wang, Ming Gao, Wenli Luo and Hongyan Cai \\ State Key Laboratory of EOR, RIPED, Beijing, China
}

In this paper, a composite sample (VES and $\mathrm{SiO}_{2}$ nanoparticle) was used to overcome the deficiencies of polymer. The rheological character of the VES/nanoparticles hybrid and flow behavior in porous media were examined. It was found that $\mathrm{SiO}_{2}$ nanoparticles exhibited viscosifying action and improved the oil tolerance. In addition, the VES solution without nanoparticles showed a lower capacity to recover oil, which might be attributed to the fact that wormlike micelles would be destroyed in crude oil. On the contrary, an enhanced oil recovery of $9.68 \%$ was achieved in the composited experiment for the VES sample with

OPEN ACCESS

Edited by:

Songyan $\mathrm{Li}$

China University of Petroleum

(Huadong), China

Reviewed by:

Hairong Wu,

China University of Petroleum, China

Mingwei Zhao,

China University of Petroleum

(Huadong), China

${ }^{*}$ Correspondence:

Zhaoxia Liu

zhaoxliu@163.com

Specialty section:

This article was submitted to Advanced Clean Fuel Technologies, a section of the journal

Frontiers in Energy Research

Received: 24 August 2020

Accepted: 08 January 2021

Published: 23 February 2021

Citation:

Liu Z, Wang Q, Gao M, Luo W and Cai $H$ (2021) Study of Rheological

Property and Flow Behavior for Nanoparticles Enhanced VES System

in Porous Media.

Front. Energy Res. 9:598177.

doi: 10.3389/fenrg.2021.598177 nanoparticles which is relatively stable with oil.

Keywords: worm-like, nano-SiO ${ }_{2}$, rheology, enhanced oil recovery, viscoelastic surfactant, worm

\section{INTRODUCTION}

Viscoelastic surfactant (VES) fluids, generally formed by wormlike micelles, have been utilized as completion or stimulation agents in the oil and gas industry (Jeffrey Giacomin et al., 2008). Durga P. Acharya discussed the formation of wormlike micelles and the evolution of rheological properties in different mixed surfactant systems (Zhang, et al., 2018; Chu, et al., 2010). Lstvan Lakatos evaluated the VES fluid as a mobility control agent. It shows that a slug-type injection protocol is more efficient than the continuous injection of any single displacement fluids (Lakatos, et al., 2007). Michael Golombok carried out experiments on inert glass cores in the range of $45-2,200 \mathrm{mD}$. By analogy they considered their observations to correspond to permeability thickening, although it was understood that the permeability was fixed and the apparent viscosity increased. For the range of permeabilities that are applicable to oil reservoirs, the apparent viscosities observed at high permeabilities are around 10 times that of the low permeabilities (Golombok and van der Wijst, 2013).

Recent work has shown the advantageous use of nanoparticles in VES fluid systems, which included significantly increased thermal stability and fluid loss control properties in the fluid system (Huang and Crews, 2007; Qin, et al., 2017). It shows that when selected nanoparticles are added to a VES solution, they will associate or "pseudo-crosslink" the VES micelles together through charge attraction and surface adsorption (Huang, 2007). Ranjini Bandyopadhyay and A.K. Sood studied the effects of the addition of submicrometer-sized colloidal silica spheres on the linear and nonlinear rheology of semidilute solutions of a viscoelastic gel (Bandyopadhyay and Sood, 2005). The oscillatory rheological measurements for nanoparticles in viscoelastic surfactant fluids noted that the nanoparticles apparently strengthened the micelle-micelle interactions. Lab proppant settling tests demonstrated that the nanoparticle induced VES micelle network structures that dramatically increased the capacity of the surfactant fluid to suspend and transport proppant in well treatments 
(Huang et al., 2008; Huang and Crews, 2007; Huang and Crews, 2008; Crews and Huang, 2008; Crews and Ahmed, 2012; Gurluk, et al., 2013). M.F. Fakoya thinks the nanofluids could be used for hydraulic fracturing (Fan et al., 2011; Fakoya and Shah, 2013; Fakoya and Shah, 2014). They also investigated the pyroelectric barium titanate $\left(\mathrm{BaTiO}_{3}\right)$ nanoparticle and found the viscosity of the MES micelle solution increased with the temperature within a certain range because of the pyroelectric effect of the nanoparticles (Luo, et al., 2012; Helgeson, et al., 2010).

For the majority of oil reservoirs, large amounts of oil are still left unrecovered after extensive water flooding. Chemical EOR technology is the most promising tertiary recovery technique to both improve sweep and displacement efficiency. The wellknown process to improve sweep efficiency consists in injecting polymer solution. This process known as polymer flooding has been widely used at large scale especially at Daqing field in China (Morvan, et al., 2009). For conventional polymer flooding, the injection of concentrated polymer solutions raises injectivity issues and requires higher injection pressure with the risk of exceeding the formation fracturing pressure. Micelles behave like polymer chains. In particular, at high concentrations, they form a network of topological entanglements and, as a result, the solution acquires viscoelastic properties. However, compared to polymers, the micellar chains of surfactants can reversibly break and recover. However, unlike polymers in solutions, wormlike micelles undergo breaking and recombination (Chu et al., 2010). Mikel Morvan studied the viscoelastic behavior, thermal stability, and adsorption on sandstone. They suspected that WLMs could increase the $29 \%$ of oil recovery vs. water flooding (Morvan, et al., 2012a; Degre, et al., 2012; Morvan, et al., 2012b). Joris van Santvoort studied the retardation ratio of VES in the different permeability core. Flow resistance in a high permeability core was shown to be significantly higher than in a low permeability core. Increasing the concentration of surfactant and co-solute led to an enhanced resistance factor (Zhu et al., 2013; Joris van and Golombok, 2015).

Herein, a novel hybrid sample (VES and $\mathrm{SiO}_{2}$ nanoparticle) has been studied to overcome the deficiencies of HPAM. We investigated the effects of nano- $\mathrm{SiO}_{2}$ on the rheology of VES solutions and the influencing parameters, including surfactant concentrations, nanoparticle concentrations, particle diameters, and $\mathrm{NaCl}$ concentrations. We also compared the ability of the VES system in enhancing oil recovery in the presence and absence of nanoparticles. Our investigation may provide a new idea for the development of an oil recovery agent.

\section{EXPERIMENTAL}

\section{Materials}

The VES solutions used during the experiments are composed of sodium dodecyl sulfate (chemical pure) and lauroylamidopropyl betaine (industrial product) purchased from Sinopharm. $\mathrm{SiO}_{2}$ nanoparticles with different particle diameters including $7 \mathrm{~nm}$, $12 \mathrm{~nm}$, and $22 \mathrm{~nm}$ are those of Ludox SM, HS, and TM, were received as a gift from W. R. Grace. Sodium chloride $(\mathrm{NaCl})$ was purchased from the Xilong Scientific Company. Deionized water with an electrical resistivity of $18.2 \mathrm{M} \Omega \cdot \mathrm{cm}$ was used to prepare the solutions. Crude oil was obtained from the Shengli Oilfield in China, with a density and viscosity of $0.89 \mathrm{~g} / \mathrm{cm}^{3}$ and $80.1 \mathrm{mPa} \cdot \mathrm{s}$, respectively, at $50^{\circ} \mathrm{C}$. Component analysis results show that this oil is composed of $70.66 \mathrm{wt} \%$ saturated hydrocarbons, $20.92 \mathrm{wt} \%$ aromatic hydrocarbons, $5.83 \mathrm{wt} \%$ resions, and $2.59 \mathrm{wt} \%$ asphaltene.

\section{Rheology Test}

Rheological experiments were performed using an Anton Paar MCR301 rotational rheometer. The sample temperature was adjusted using a Peltier thermostat (Chen, et al., 2012). The viscosity of the samples was measured at different temperatures and various shear rates. During the angular frequency scan, elastic and storage moduli were determined at $50^{\circ} \mathrm{C}$ with the same rheometer (Zhu et al., 2013).

\section{Interfacial Tension Measurements}

The dynamic IFT values were measured using a Texas-500 spinning drop tensiometer (Temco, United States) (Jiang, et al., 2014). The instrument was equipped with an imageacquisition module and the IFT value could be automatically calculated according to the length and the width of the oil droplet. The temperature for all the measurements was maintained at $50^{\circ} \mathrm{C}$ using a semiconductor thermostat.

\section{Sandpack Flooding Experiment}

Flooding experiments were performed at $50^{\circ} \mathrm{C}$. A steel cylinder of 10 inches in height and 1 inch in inner diameter was filled with quartz sands of different sizes. The porosity of the porous sandpack was about $35.8 \%$. The sandpack was initially saturated with synthetic brine, and then displaced by dehydrated crude oil. Water flooding was performed until the water proportion of the output fluid was higher than $98 \%$. Afterward, the composite VES solution was injected. The difference between water flooding recovery and total recovery was calculated as the tertiary recovery increased by nanoparticle/ surfactant composite flooding. The injection rate was maintained at $0.5 \mathrm{ml} / \mathrm{min}$ (Zhu et al., 2013).

\section{RESULTS AND DISCUSSION}

\section{Rheological Properties of VES}

The viscosity of injected solutions plays a significant role in displacing crude oil during oilfield development. Consequently, it is necessary to clarify the rheological behaviors of nanoparticle/ surfactant solutions (Zhu et al., 2013).

Figure 1 shows the viscosities of VES at the shear rate of $7.34 \mathrm{~s}^{-1}$ against the percentage of LAB in the LAB/SDS mixture. The viscosity increases with the increasing $L A B$ percentage on composite surfactants until the mass ratio of LAB/SDS is 3:1, after which the viscosity begins to drop. Therefore, this proportion is used in the following experiments.

Figure 2 shows that the viscosity of VES is significantly affected by salinities. The VES viscosity increases with a 


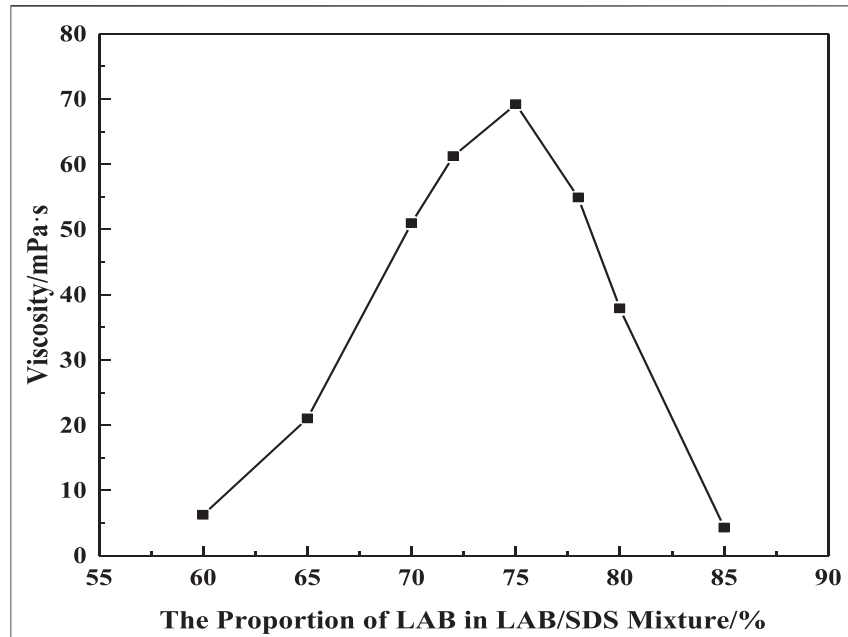

FIGURE 1 | Effect of LAB percentage on apparent viscosity ( $w$ (LBA + $\left.\mathrm{SDS})=1 \%, w(\mathrm{NaCl})=1 \%, \mathrm{~T}=50^{\circ} \mathrm{C}, \gamma=7.34 \mathrm{~s}^{-1}\right)$.

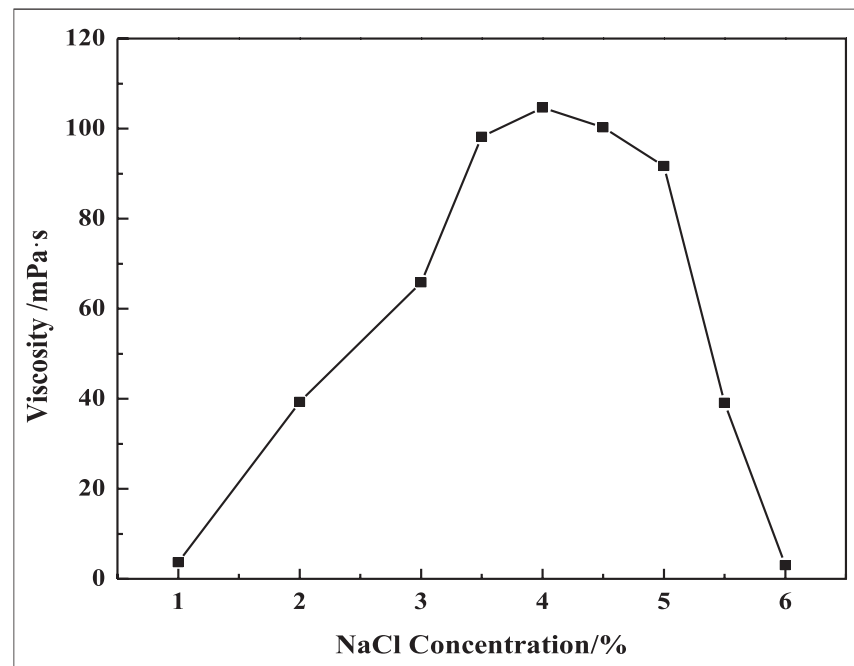

FIGURE 2 | Effect of salinity on apparent viscosity $(w($ LBA + SDS) $=$ $0.8 \%$, LBA:SDS $\left.=3: 1, \mathrm{~T}=50^{\circ} \mathrm{C}, \gamma=7.34 \mathrm{~s}^{-1}\right)$.

salinity until $4 \%$, before which the $\mathrm{NaCl}$ could compress the diffuse electric double-layer of the surfactants. And it causes more surfactant molecules to go into the micelle promoting the growth of entangled wormlike micelles. But if the salinity is more than $4 \%$, the diffuse electric double layer would be over compressed. The surface charge of the micelle is too low, making the micelles coil and decreases the fluid dynamics radius.

The viscosity variation of the VES solution against surfactant concentration is shown in Figure 3. The solution viscosity increases as the concentration rises especially when the surfactant concentration is more than $0.4 \%$. The viscosity increases from $13.79 \mathrm{mPa} \cdot \mathrm{s}$ to $185.49 \mathrm{mPa} \cdot \mathrm{s}$ as the concentration increases from $0.4 \%$ to $1 \%$, at which concentration the micelles could form a large space structure with higher viscosity.

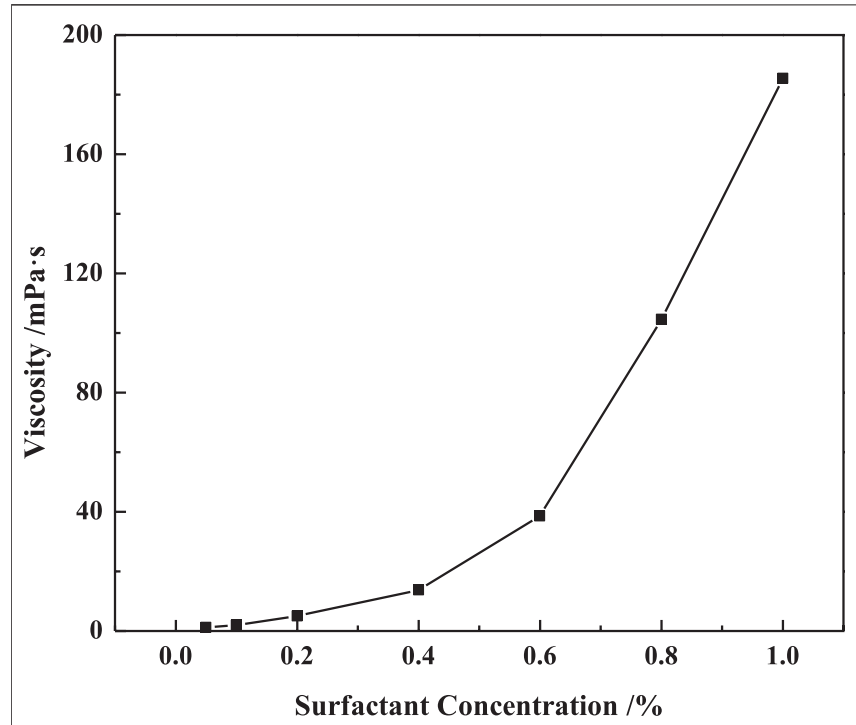

FIGURE 3 | Effect of surfactants concentration on apparent viscosity $\left(\right.$ LBA:SDS $\left.=3: 1, \mathrm{~T}=50^{\circ} \mathrm{C}, w(\mathrm{NaCl})=4 \%, \gamma=7.34 \mathrm{~s}^{-1}\right)$.

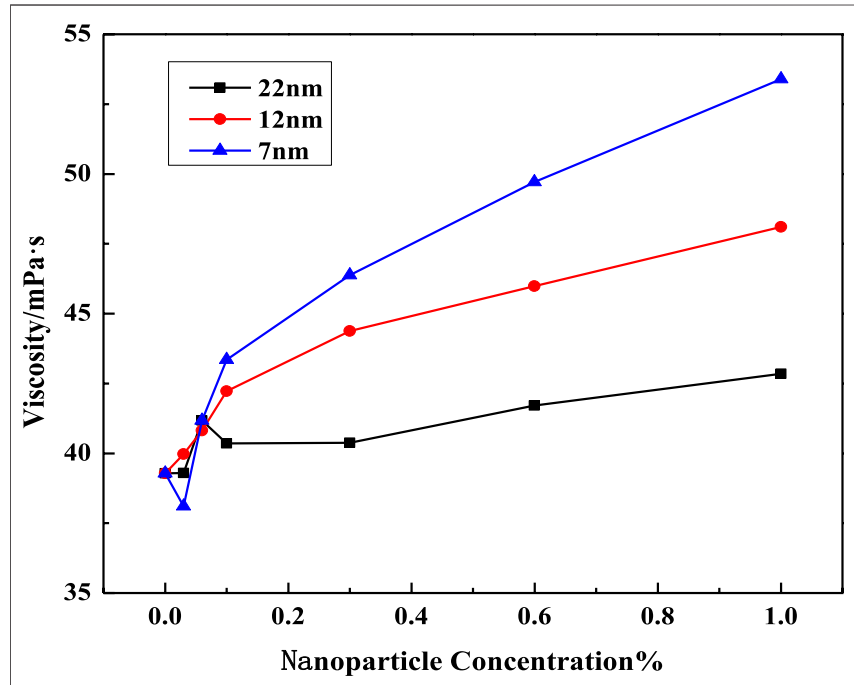

FIGURE 4 | Effect of $\mathrm{SiO}_{2}$ concentration on solution viscosity at different nanoparticle diameters $\left(w(\mathrm{LBA}+\mathrm{SDS})=0.8 \%\right.$, LBA:SDS $=3: 1, \mathrm{~T}=50^{\circ} \mathrm{C}, w$ $\left.(\mathrm{NaCl})=2 \%, \gamma=7.34 \mathrm{~s}^{-1}\right)$.

\section{Rheological Behaviors of VES Samples With $\mathrm{SiO}_{2}$ Nanoparticles}

The curves of VES viscosity against the nanoparticle concentration at different salinities is shown in Figures 4-6. It shows that the viscosity of the VES solution at the same surfactant concentration could be apparently improved. These results can be interpreted in terms of the growth of entangled wormlike micelles, followed by the formation of bilayers due to the adsorption of the headgroups on $\mathrm{SiO}_{2}$ surfaces (Bandyopadhyay and Sood, 2005). It also shows that the $\mathrm{SiO}_{2}$ nanoparticles with a smaller diameter have a higher viscosifying 


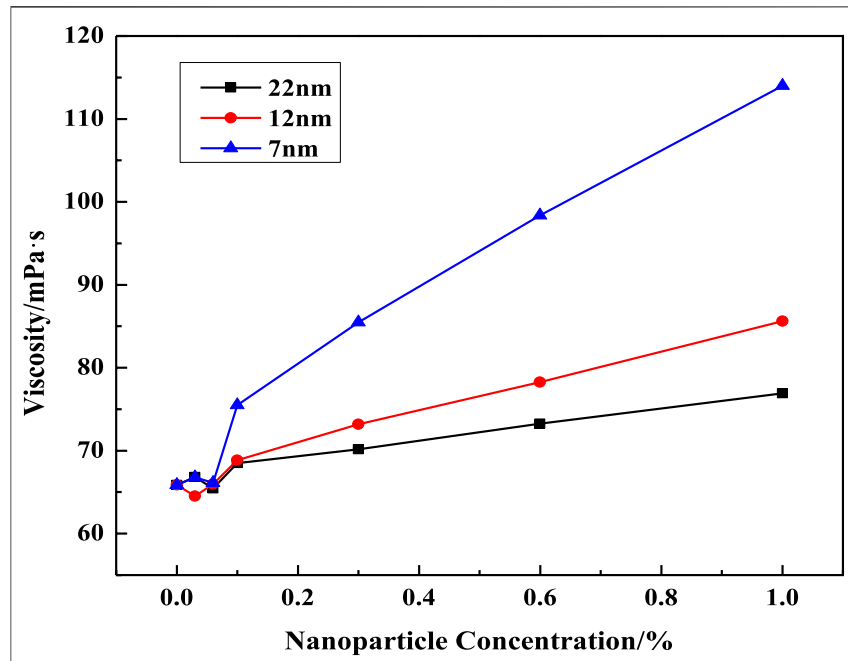

FIGURE 5 | Effect of $\mathrm{SiO}_{2}$ concentration on solution viscosity at different nanoparticle diameters $\left(w(\mathrm{LBA}+\mathrm{SDS})=0.8 \%, \mathrm{LBA}: \mathrm{SDS}=3: 1, \mathrm{~T}=50^{\circ} \mathrm{C}, w\right.$ $\left.(\mathrm{NaCl})=3 \%, \gamma=7.34 \mathrm{~s}^{-1}\right)$.

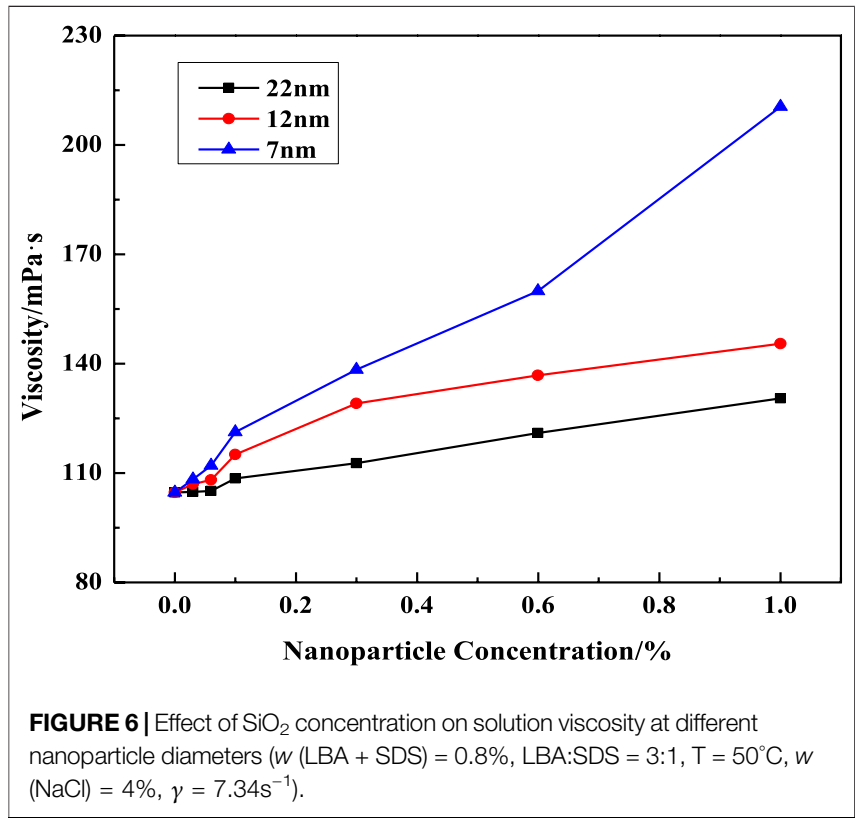

ability. This could be attributed to the fact that smaller nanoparticles have a higher specific surface area and higher amounts at a certain concentration, which may provide more crosslinking points. Therefore, $7 \mathrm{~nm} \mathrm{SiO}_{2}$ nanoparticles were used in the following experiments.

The influence of silica particle concentration, salinity, surfactant concentration, and temperature on VES viscosity is shown in Figures 7-9. In Figure 7, the solution viscosity increases with the rise of $\mathrm{SiO}_{2}$ concentration and salinity. Especially, the test sample containing $4 \% \mathrm{NaCl}$ presents a wide range of viscosity increase with the nanoparticle addition compared with the low salinity solution, which means that nanoparticles enhanced the viscosity of VES

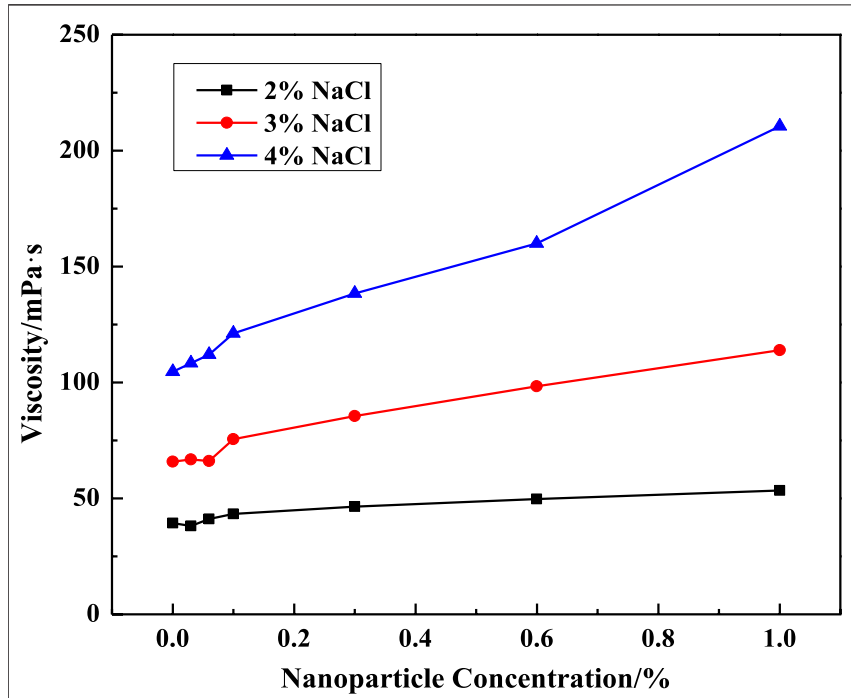

FIGURE 7 | Effect of $\mathrm{SiO}_{2}$ concentration on solution viscosity at different salinities $\left(w(L B A+S D S)=0.8 \%\right.$, LBA:SDS $\left.=3: 1, T=50^{\circ} \mathrm{C}, \gamma=7.34 \mathrm{~s}^{-1}\right)$.

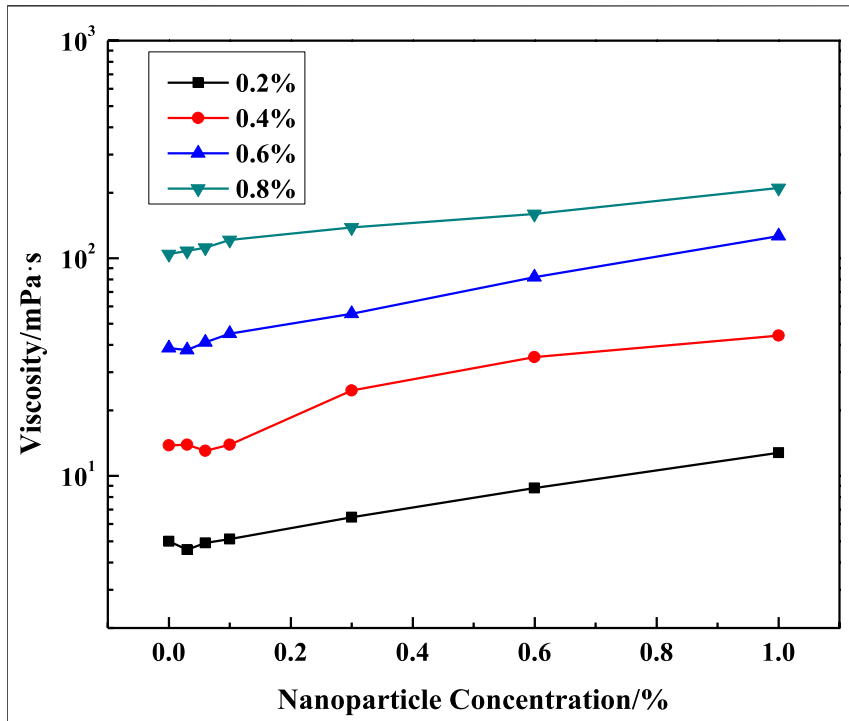

FIGURE 8 | Effect of $\mathrm{SiO}_{2}$ concentration on solution viscosity at different surfactant concentrations $\left(\mathrm{LBA}: \mathrm{SDS}=3: 1, \mathrm{~T}=50^{\circ} \mathrm{C}, w(\mathrm{NaCl})=4 \%, \gamma=\right.$ $\left.7.34 \mathrm{~s}^{-1}\right)$.

solutions by increasing the entanglements of wormlike micelles. As expected, the viscosity of the VES solution continuously decreases at increasing temperatures, which is similar to that of the system without particles.

Rheological evaluation of the viscoelastic nature of the surfactant fluids with and without nanoparticles was carried out. Figure 10 shows the dependence of viscosity of the VES solution against the silica particle concentration on shear rate. At low shear rates, the viscosity of the VES solution without particles remains unchanged (Newtonian viscosity); then, its value 


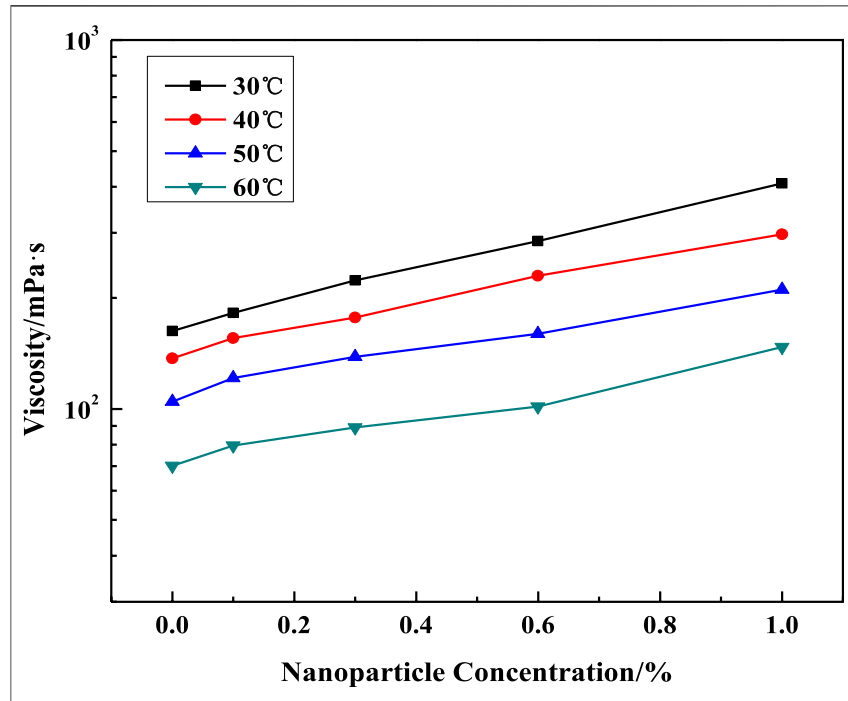

FIGURE 9 | Effect of $\mathrm{SiO}_{2}$ concentration on solution viscosity at different temperatures $(w(\mathrm{LBA}+\mathrm{SDS})=0.8 \%, \mathrm{LBA}: \mathrm{SDS}=3: 1, w(\mathrm{NaCl})=4 \%, \gamma=$ $\left.7.34 s^{-1}\right)$.

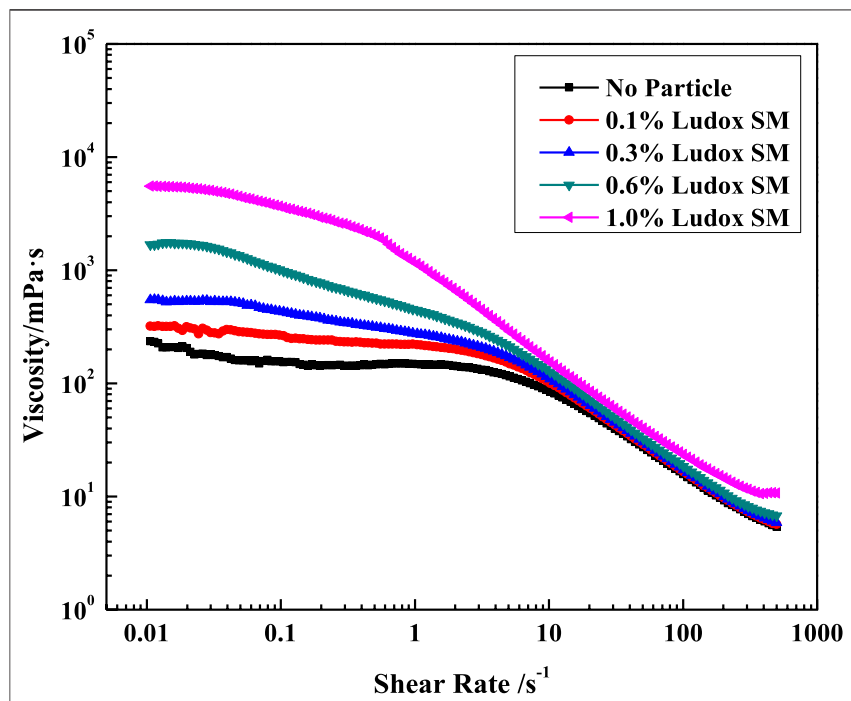

FIGURE 10 | Effect of $\mathrm{SiO}_{2}$ concentration on solution viscosity at different shear rates. $\left(w(\mathrm{LBA}+\mathrm{SDS})=0.8 \%, \mathrm{LBA}: \mathrm{SDS}=3: 1, \mathrm{~T}=50^{\circ} \mathrm{C}, w\right.$ $(\mathrm{NaCl})=4 \%$.

decreases as the shear rate grows above $2 \mathrm{~s}^{-1}$, which is associated with the orientation of micellar chains along the flow direction and possibly with their partial break. And adding particles has a significant effect on the viscosity of VES solutions especially at low shear rates. Note that $1 \%$ nanoparticles increased the viscosity of the VES fluid by more than 23 times at the shear rate of $0.1 \mathrm{~s}^{-1}$, which may be caused by the influence of particles on the network structure of micelles. But at high shear rates, the effect of the nanoparticles is weakened.

The G' and G" viscous-elastic behavior between the VES fluids with and without nanoparticles at different shear stress and

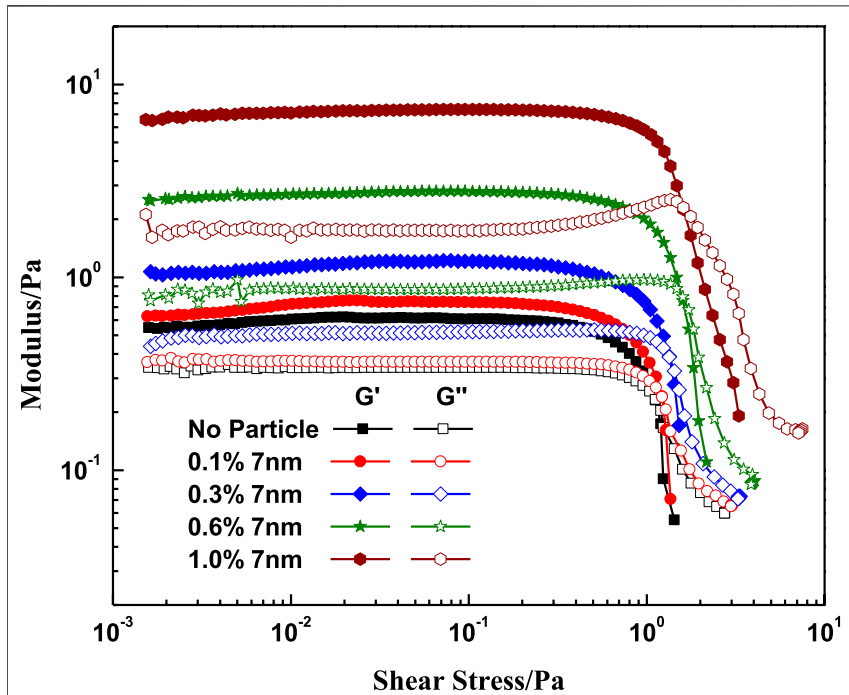

FIGURE 11 | Effect of $\mathrm{SiO}_{2}$ concentration on the modulus with different shear stress. $\left(w(\mathrm{LBA}+\mathrm{SDS})=0.8 \%, \mathrm{LBA}: \mathrm{SDS}=3: 1, \mathrm{~T}=50^{\circ} \mathrm{C}, w(\mathrm{NaCl})=\right.$ $4 \%$, frequency $=1 \mathrm{~Hz}$ ).

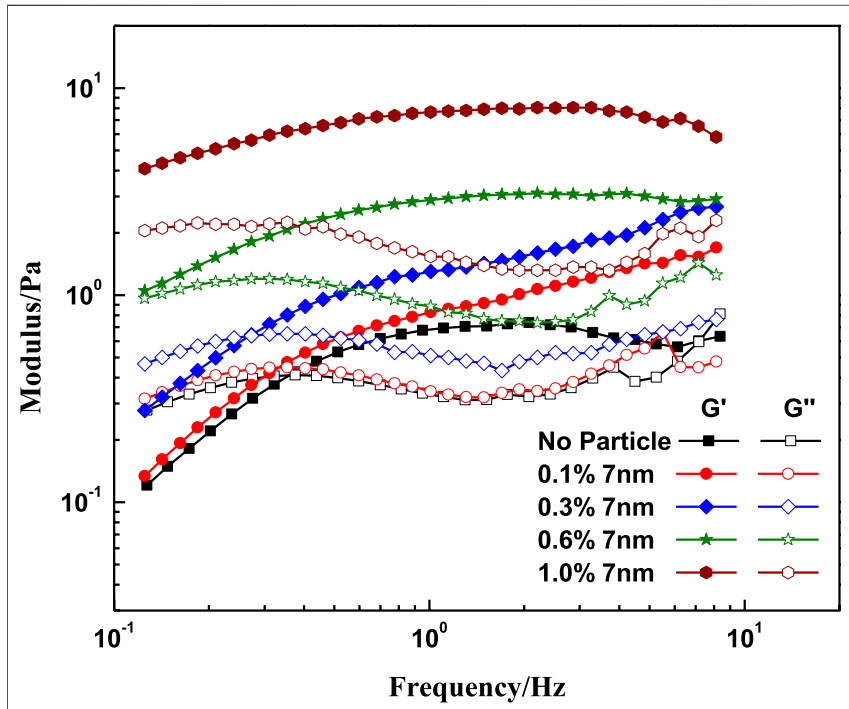

FIGURE 12 | Effect of $\mathrm{SiO}_{2}$ concentration on the modulus at different frequencies. $\left(w(\mathrm{LBA}+\mathrm{SDS})=0.8 \%, \mathrm{LBA}: \mathrm{SDS}=3: 1, \mathrm{~T}=50^{\circ} \mathrm{C}, w(\mathrm{NaCl})=\right.$ $4 \%$, shear stress $=0.01 \mathrm{~Pa})$.

frequency are shown in Figures 11, 12. Figure 11 shows that G' and G" of the VES solution with or without particles were constant at low shear stress and significantly decreased at high shear stress above $0.8 \mathrm{~Pa}$. Within the plateau area, the system shows strong elastic properties. And in the range of high shear stress, the loss modulus exceeds the value of the storage modulus. Meanwhile, adding nanoparticles increases both G' and G', which indicated that the addition of small amounts of nanoparticles to the VES solution resulted in the strengthening of the micelle-micelle associations and elongated micelle structures in the fluids. The intersection point of the $G$ ' and 


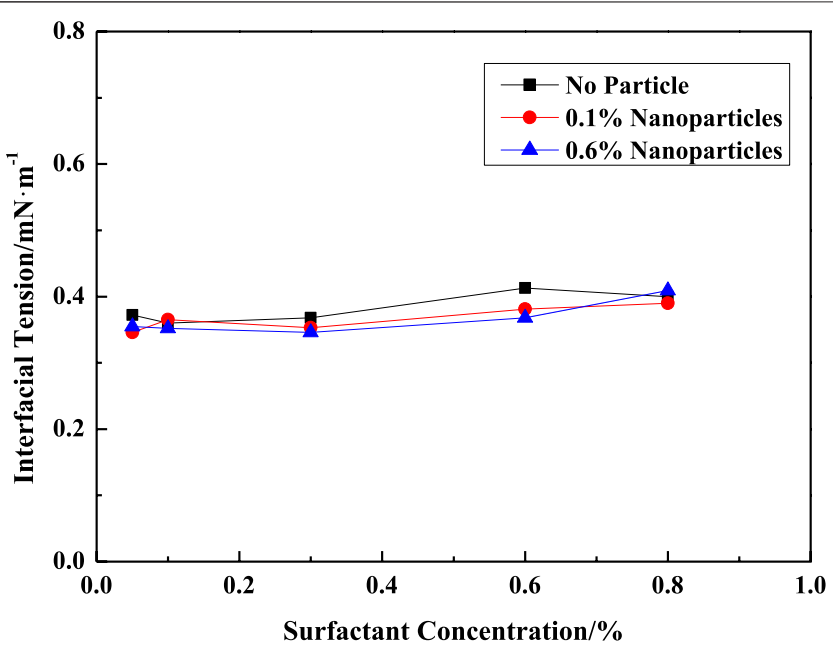

FIGURE 13 | IFT between the VES solution and Zhuangxi crude oil. (A) $\left(w(\mathrm{LBA}+\mathrm{SDS})=0.8 \%, \mathrm{LBA}: \mathrm{SDS}=3: 1, \mathrm{~T}=50^{\circ} \mathrm{C}, w(\mathrm{NaCl})=4 \%, \mathrm{~K}=\right.$ $500 \mathrm{mD})$. (B) $\left(w(\mathrm{LBA}+\mathrm{SDS})=0.8 \%, \mathrm{LBA}: \mathrm{SDS}=3: 1, \mathrm{~T}=50^{\circ} \mathrm{C}, w(\mathrm{NaCl})=4 \%\right.$, $\mathrm{K}=1500 \mathrm{mD})$. (C) $\left(w\left(\mathrm{SiO}_{2}\right)=0.8 \%, w(\mathrm{LBA}+\mathrm{SDS})=0.8 \%\right.$, LBA:SDS $=$ $\left.3: 1, \mathrm{~T}=50^{\circ} \mathrm{C}, w(\mathrm{NaCl})=4 \%, \mathrm{~K}=400 \mathrm{mD}\right)$. (D) $\left(w\left(\mathrm{SiO}_{2}\right)=0.8 \%, w(\mathrm{LBA}+\right.$ $\left.\mathrm{SDS})=0.8 \%, \mathrm{LBA}: \mathrm{SDS}=3: 1, \mathrm{~T}=50^{\circ} \mathrm{C}, w(\mathrm{NaCl})=4 \%, \mathrm{~K}=1900 \mathrm{mD}\right)$.

G" right shifts with the increase of the nanoparticle concentration, which indicates that the $\mathrm{SiO}_{2}$ has a greater contribution to G'.

Figure 12 shows that at low frequency the loss modulus exceeds the value of storage modulus, and the elastic properties dominate at high frequency. Meanwhile, adding nanoparticles increases both G' and G", and the intersection point of the G' and G" left shift with the increases of the nanoparticles concentration indicates that the $\mathrm{SiO}_{2}$ has a greater contribution to G' which is similar to the results of Figure 11.

\section{Interfacial Tension Between VES Solution and Oil}

Figure 13 shows the interfacial tensions between Zhuangxi crude oil and surfactant/silica solutions of various concentrations at $50^{\circ} \mathrm{C}$. The interfacial tension is about $0.38 \mathrm{mN} / \mathrm{m}$ within a wide range of surfactant concentrations. And adding $\mathrm{SiO}_{2}$ has less effect on the IFT.

\section{Oil Displacement Test}

Variations of recovery factors, water contents, and displacement pressures with injected volumes are plotted in Figure 14 of the VES solutions with and without nanoparticles in different permeability media. Sandpack parameters, flooding processes, and the oil recovery results are summarized in Table $\mathbf{1 .}$

Less than $5 \%$ oil recovery was achieved by the VES solution without particles (Figures 14A,4B). As shown in Figures 14C, $4 \mathrm{D}$, the oil recovery factor of the hybrid sample (VES solution with silica particles) was $9.68 \%$ in the high permeability zone, which was larger than that in low permeability media. In order to find the reason why VES has no effect on oil recovery, the apparent viscosity of VES with different oil ratios was measured, as shown in Figure 15.
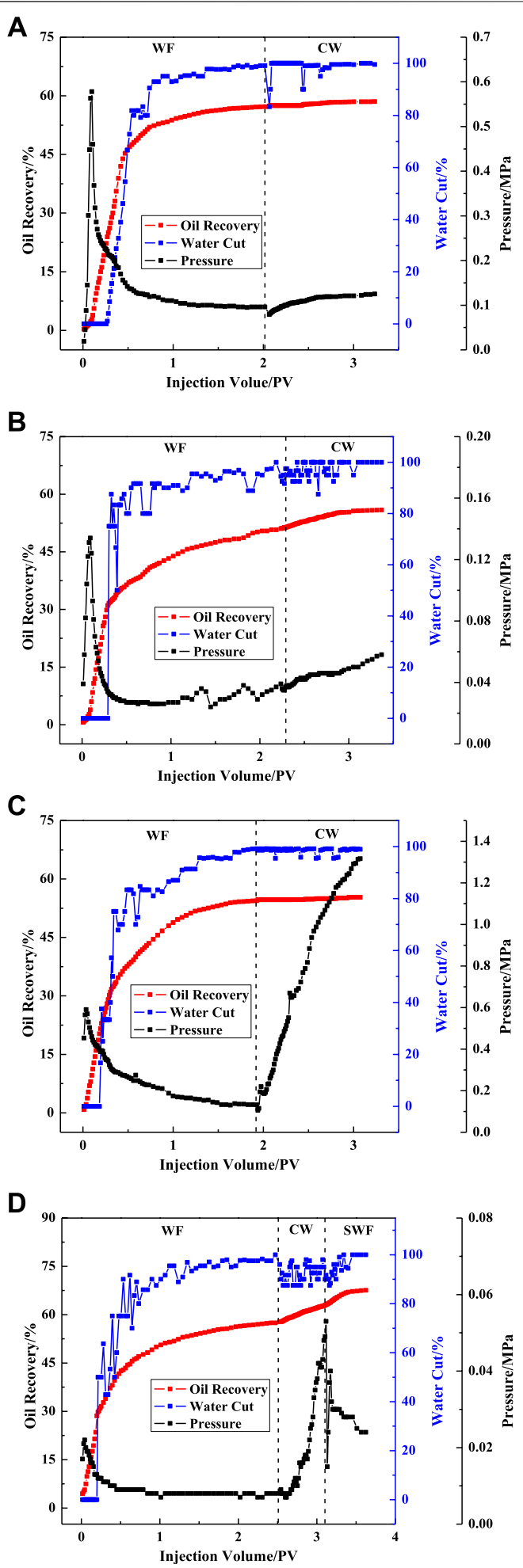

FIGURE 14 | Recovery factor, water cut, and flooding pressure plotted as a function of injected volume of different samples (WF = water flooding; $\mathrm{CW}=$ chemical flooding; SWF = subsequent water flooding).

It shows that oil has great influence on the apparent viscosity of the VES solution. Note that only $1 \%$ oil decreased the viscosity of the VES solution without nanoparticles by more than $97 \%$ 
TABLE 1 | Sandpack parameters, displacement process, and the results of these oil displacement tests.

$0.8 \%($ LAB:SDS $=3: 1)+4 \% \mathrm{NaCl}$

$\begin{array}{cc}500 & 1,500 \\ 88.56 & 88.16 \\ 57.36 & 51.37 \\ 1.14 & 4.52 \\ 58.50 & 55.89\end{array}$

58.50
$0.8 \%($ LAB:SDS $=3: 1)+4 \% \mathrm{NaCl}+$ $0.8 \% 7 \mathrm{~nm} \mathrm{SiO} 2$

\section{Permeability/mD}

Initial oil saturation $\mathrm{S}_{\mathrm{o}} / \%$

Primary recovery efficiency $\mathrm{R}_{\mathrm{o}} / \%$

Secondary recovery factor $R_{0} / \%$

Overall recovery efficiency $R_{0} / \%$

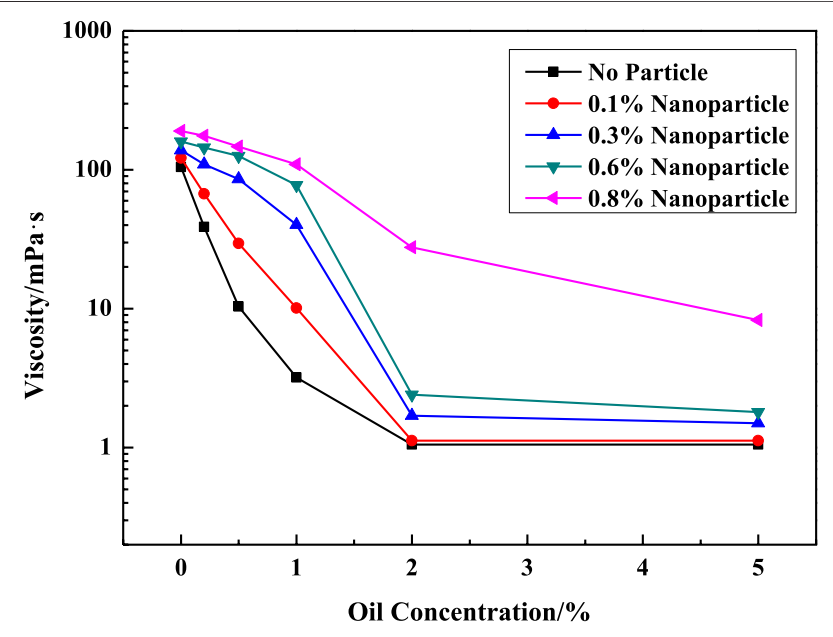

FIGURE 15 | Effect of oil ratio on apparent viscosity in different systems. $\left(w(\mathrm{LBA}+\mathrm{SDS})=0.8 \%, \mathrm{LBA}: \mathrm{SDS}=3: 1, \mathrm{~T}=50^{\circ} \mathrm{C}, w(\mathrm{NaCl})=4 \%, \gamma=\right.$ $\left.7.34 s^{-1}\right)$.

which indicates the oil break of the structure of WLMs. But the presence of particles could weaken the influence of oil. The viscosity of the system with $0.8 \% \mathrm{SiO}_{2}$ only decreased about $43 \%$ when mixed with $1 \%$ crude oil.

The poor oil recovery efficiency of the VES solution without particles may be attributed to the fact that VES micelles could be easily destructed while in residual crude oil. On the contrary, the structure of VES in the presence of nanoparticles could be significantly enhanced, and thus the water/oil mobility ratio could be improved, resulting in a higher oil recovery (Zhu et al. 2013). The main reason for the invalidity of the hybrid samples in low permeability sandpacks can be ascribed to the bridging of nanoparticles at the inlet, a consequence of the continuously increasing injection pressures.

\section{CONCLUSION}

The rheological behaviors of the $\mathrm{VES} / \mathrm{SiO}_{2}$ nanoparticle hybrid and sandpack flooding experiments were examined. It was found that the $\mathrm{SiO}_{2}$ nanoparticle exhibited viscosifying action and improved oil tolerance. In addition, the poor oil recovery efficiency of the solution without nanoparticles may be attributed to the destruction of the VES micelles upon contacting the residual oil. On the contrary, $9.68 \%$ of oil recovery was achieved from the VES and nanoparticle samples in the high permeability sandpack flooding test for the VES sample with nanoparticles which is relatively stable with oil in order to produce more oil. However, the nanoparticles bridging off the sandpack inlet restrict its use in a low permeability reservoir.

\section{DATA AVAILABILITY STATEMENT}

The original contributions presented in the study are included in the article/Supplementary Material, further inquiries can be directed to the corresponding author.

\section{AUTHOR CONTRIBUTIONS}

ZL, QW, and HC contributed to the conception and design of the work; QW, MG, and WL contributed to the acqusition and analysis of data for the work; QW, MG, and WL drafted the work; ZL and HC revise the work critically; All the five authors made the final approval of the version to be published; All the five authors made the agreement to be accountable for all aspects of the work in ensuring that questions related to the accuracy or integrity of any part of the work are appropriately investigated and resolved.

\section{ACKNOWLEDGMENTS}

We acknowledge the Natural Science Foundation of China (51474234 and 51574266), the Natural Science Foundation of Shandong Province, China (ZR2014EZ002 and ZR2015EQ013), and the Fok Ying Tung Education Foundation (151049) for supporting this work. 


\section{REFERENCES}

Bandyopadhyay, R., and Sood, A. K. (2005). Effect of silica colloids on the rheology of viscoelastic gels formed by the surfactant cetyl trimethylammonium tosylate. J. Colloid. Interface. Sci. 283 (2), 585-591. doi:10.1016/j.jcis.2004.09.038

Chen, Q., Wang, Y., Lu, Z., and Feng, Y. (2012). Thermoviscosifying polymer used for enhanced oil recovery: rheological behaviors and core flooding test. Polymer Bulletin. 70, 391-401. doi:10.1007/s00289-012-0798-7

Chu, Z., Feng, Y., Su, X., and Han, Y. (2010). Wormlike micelles and solution properties of a C22-tailed amidosulfobetaine surfactant. Langmuir 26, 7783-7791. doi:10.1021/la904582w

Crews, J. B., and Ahmed, M. G. (2012). "Nanoparticle-associated surfactant micellar fluids: an alternative to crosslinked polymer systems," in SPE 157055 was prepared for presentation at the SPE international oilfield nanotechnology conference held in Noordwijk, Noordwijk, Netherlands, June 12-14, 2012.

Crews, J. B., and Huang, T. (2008). "Performance enhancements of Viscoelastic surfactant stimulation fluids with nanoparticles," in SPE 113533 was prepared for presentation at the 2008 SPE Europec/EAGE annual conference and exhibition held in Rome, Rome, Italy, June 9-12, 2008.

Degre, G., Morvan, M., and Beaumount, J. (2012). "Viscosifying surfactant technology for chemical EOR: a reservoir case," in SPE 154675 was prepared for presentation at the spe EOR conference at oil and gas west asia held in Muscat, Muscat, Oman, April 16, 2012, 16-18.

Fakoya, M. F., and Shah, S. N. (2013). "Rheological properties of surfactant-based and polymeric nano-fluids," in SPE 163921 was prepared for presentation at the SPE/ICoTA coiled tubing \& well intervention conference \& exhibition held in the Woodlands, Woodlands, TX, United States, March 26-27, 2013.

Fakoya,, M. F., and Shah, S. N. "Enhancement of filtration properties in surfactantbased and polymeric fluids by nanoparticles," in SPE-171029-MS was prepared for presentation at the SPE Eastern Regional Meeting held Charleston, Charleston, WV, United States, October 21-23, 2014.

Fan, H., Luo, M., Jia, Z., and Hou, T. (2011). Effect of Nano-SiO $\mathrm{N}_{2}$ on the rheology of anionic viscoelastic solutions formed by the biodegradable surfactant fatty acid methyl ester sulfonate. Materials Sci. Forum. 694, 64-67. doi:10.4028/www. scientific.net/msf.694.64

Golombok, M., and van der Wijst, R. (2013). Permeability thickening fluids for improved secondary oil recovery. J. Petrol. Sci. Engineer. 110, 22-26. doi:10. 1016/j.petrol.2013.08.040

Gurluk, M. R., Nasr-El-Dina, H. A., and Crews, J. B. (2013). "Enhancing the performance of viscoelastic surfactant fluids using nanoparticles," in SPE 164900 was prepared for presentation at the EAGE Annual Conference \& Exhibition incorporation SPE Europec held in London, London, United Kingdom, June 10-13, 2013. doi:10.2118/164900-MS

Helgeson, M. E., Hodgdon, T. K., Kaler, E. W., Wagner, N. J., and Vethamuthu, K. P. A. (2010). Formation and rheology of viscoelastic "double networks" in wormlike micelle-nanoparticle mixtures. Langmuir 26 (11), 8049-8060. doi:10. 1021/la100026d

Huang, T., and Crews, J. B. (2007). "Nanotechnology applications in viscoelastic surfactant stimulation fluids," in SPE 107728 presented at the 2007 SPE European formation damage conference held in Scheveningen, Scheveningen, Netherlands, May 30, 2007.

Huang, T., and Crews, J. B. (2008). "Do viscoelastic-surfactant diverting fluids for acid treatments need internal breakers," in SPE 112484 was prepared for presentation at the 2008 SPE International Symposium and Exhibition on Formation Damage Control held in Lafayette, Lafayette, LA, United States, February 13-15, 2008.

Huang, T., Crews, J. B., and Willingham, J. R. (2008). "Nanopartiicles for faomation fines fixation and improving performance of surfactant structure fluids," in IPTC 12414 prepared for presentation at the international petroleum technology conference held in Kuala Lumpur, Kuala Lumpur, Malaysia, December 3-5, 2008. doi:10.2523/IPTC-12414-MS

Huang, T. (2007). "Nanotechnology applications in viscoelastic surfactant stimulation fluids," in Proceedings of European formation damage conference EFDC, Scheveningen, Netherlands, May 30, 2007.

Jeffrey Giacomin, A., Albert, C., Gary, L. L., and Ralph, H. C. (2008). Nanoparticle associated surfactant micellar fluids. AIP Conf. Proc. 1027, 857. doi:10.1063/1. 2964872

Jiang, P., Li, N., Ge, J., Zhang, G., Wang, Y., Chen, L., et al. (2014). Efficiency of a sulfobetaine-type surfactant on lowering IFT at crude oil-formation water interface. Colloi. Sur. A: Physicochem. Engineer. Aspects. 443, 141-148. doi:10. 1016/j.colsurfa.2013.10.061

Joris van, S., and Golombok, M. (2015). Viscoelastic surfactants for diversion control in oil recovery. J. Petrol. Sci. Engineer. 135, 671-677. doi:10.1016/j. petrol.2015.10.030

Lakatos, L., Toth, J., Bodi, T., Lakatos-Szabo, J., Berger, P. D., and Lee, C. (2007). "Application of viscoelastic surfactants as mobility-control agents in lowtension surfactant floods" in SPE 106005 was prepared for presentation at the 2007 SPE international symposium on oilfield chemistry held in Houston, Texas, United States, February 28, 2007.

Luo, M., Jia, Z., Sun, H., Lejun, L., and Qingzhi, W. (2012). Rheological behavior and microstructure of an anionic surfactant micelle solution with pyroelectric nanoparticle. Colloids and Surfaces A: Physicochem. 395, 267-275. doi:10.1016/ j.colsurfa.2011.12.052

Morvan, M., Degre, G., Leng, J., Masselon, J., Bouillot, A. Z., and Moreau, P. (2009). "New viscoelastic fluid for chemical EOR," in SPE 121675 was prepared for presentation at the 2009 SPE international symposium on oilfield chemistry held in the Woodiands, Woodiands, TX, United States, April 20-22, 2009.

Morvan, M., Degre, G., Beaumount, J., Dupuis, G., Zaitoun, A., and Al-Maamari, R. S. (2012a). "Optimization of viscosifying surfactant technology for chemical EOR," in SPE 154053 was prepared for presentation at the eighteenth SPE improved oil recovery symposium held in Tulsa, Tulsa, OK, United States, April 14-18, 2012.

Morvan, M., Degre, G., Beaumount, J., Colin, A., Dupuis, G., Zaitoun, A., et al. (2012b). "Viscosifying surfactant technology for heavy oil reservoirs," in SPE 157729 was prepared for presentation at the SPE Heavy Oil Conference Canada held in Calgary, Calgary, AB, Canada, June 12-14, 2012.

Qin, W., Yue, L., Liang, G., Jiang, G., Jiang, Y, and Liu, Y. (2017). Effect of multiwalled carbon nanotubes on linear viscoelastic behavior and microstructure of zwitterionic wormlike micelle at high temperature. Chem. Engineer. Res. Design. 123, 12-23. doi:10.1016/j.cherd.2017.04.027

Zhang, Y., Dai, C., Yao, Q., Xiqun, F., Jianfeng, J., Yining, W., et al. (2018). Rheological properties and formation dynamic filtration damage evaluation of a novel nanoparticle-enhanced VES fracturing system constructed with wormlike micelles. Colloids Surfaces A: Physicochem. Engineer. Aspects. 553, 244-252. doi:10.1016/j.colsurfa.2018.05.065

Zhu, D., Zhang, J., Han, Y., Wang, H., and Feng, Y. (2013). Laboratory study on the potential EOR use of HPAM/VES hybrid in high-temperature and HighSalinity oil reservoirs. J. Chem. 2013, 927519. doi:10.1155/2013/927519

Conflict of Interest: The authors declare that the research was conducted in the absence of any commercial or financial relationships that could be construed as a potential conflict of interest.

Copyright (c) 2021 Liu, Wang, Gao, Luo and Cai. This is an open-access article distributed under the terms of the Creative Commons Attribution License (CC BY). The use, distribution or reproduction in other forums is permitted, provided the original author(s) and the copyright owner(s) are credited and that the original publication in this journal is cited, in accordance with accepted academic practice. No use, distribution or reproduction is permitted which does not comply with these terms. 